\title{
Characterization of Zircaloy-4 after Gaseous Hydriding at the Temperature Range of $350-600^{\circ} \mathrm{C}$
}

\author{
R. Sigit ${ }^{1,2}$, H. Suwarno* and B. Soegijono ${ }^{2}$ \\ ${ }^{1}$ Center for Nuclear Fuel Technology, National Nuclear Energy Agency \\ Puspiptek Area, Serpong, Tangerang Selatan 15314, Indonesia \\ ${ }^{2}$ Department of Physics, Faculty of Mathematics and Science, University of Indonesia \\ Depok, West Java, Indonesia
}

\section{ARTICLE INFO}

\section{Article history:}

Received 5 January 2016

Received in revised form 15 June 2016

Accepted 20 August 2016

\section{Keywords:}

Zircaloy-4

Hydriding

Hydride phase

Microstructure evolution

\begin{abstract}
A B S T R A C T
The degradation of the mechanical properties of zircaloy-4 as nuclear fuel cladding is inevitable due to its interaction with hydrogen during normal reactor operation. This experiment observed the occurence of hydride phases after gaseous hydriding with hydrogen at elevated temperature, and their effects were evaluated based on the material's microstructure and mechanical properties. The zircaloy- 4 cladding materials were annealed for two hours. It was followed by hydriding with the pressure from 100 up to 1200 mbar at various temperatures of $350^{\circ} \mathrm{C}, 500^{\circ} \mathrm{C}$, $550^{\circ} \mathrm{C}$ and $600^{\circ} \mathrm{C}$. The pressure-composition-isotherm (PCI) diagram showed that the hydrogen absorbed by specimen namely $0.18 \%$ wt, $0.38 \%$ wt, $0.44 \%$ wt and $0.74 \%$ wt at $350^{\circ} \mathrm{C}, 500^{\circ} \mathrm{C}, 550^{\circ} \mathrm{C}$ and $600^{\circ} \mathrm{C}$, respectively. This result confirmed that the hydrogen content were $10,128,250$, and $1357 \mathrm{ppm}$ at $350^{\circ} \mathrm{C}, 500^{\circ} \mathrm{C}$, $550^{\circ} \mathrm{C}$, and $600^{\circ} \mathrm{C}$, respectively, as measured by an $\mathrm{ONH}$ analyzer. X-ray diffraction showed that $\delta$-hydride peaks were very weak based on fitting with the hydride database. The results from optical microscope and scanning electron microscope confirmed the presence of hydrides at the specimens, identified by the growth of needle-like structure at those temperatures.
\end{abstract}

\section{INTRODUCTION}

The affinity of zirconium-based alloys for hydrogen has received considerable attention in the nuclear industry where these materials are used as fuel element cladding, process tubes, and structural elements. Zirconium alloys are used in water reactors because of their low capture cross-section for thermal neutrons and good mechanical and corrosion properties. Early in the alloys' application, hydrogen was identified as an embrittling agent. The source of the embrittlement was hydride precipitates that formed as platelets [1]. During reactor operation, the surface of the cladding interacts with coolant leading to the oxidation of the cladding and the release of hydrogen. There are

* Corresponding author.

E-mail address: hadis@batan.go.id

DOI: http://dx.doi.org/10.17146/aij.2016.585 three different potential sources of hydrogen, namely cathodic generated of hydrogen as a result of the corrosion of the cladding by the primary side water coolant, hydrogen gas dissolution in the primary side coolants in pressurized water reactors, and hydrogen resulting from corrosion by gases or vapors containing hydrogen in the internal plenum region of the rods [2].

Interaction between hydrogen and zirconium can be classified into three different stable phases present in the zirconium-hydrogen $(\mathrm{Zr}-\mathrm{H})$ system. Those three phases are: $\alpha \mathrm{Zr}$ with $\mathrm{H}$ in solid solution in the matrix occurs at temperatures below $500^{\circ} \mathrm{C}$; $\delta$ hydride, the $\mathrm{ZrH}_{1: 5}$ to $\mathrm{ZrH}_{1: 66}$, with a fcc structure which initially precipitates as platelets in $\alpha-\mathrm{Zr}$; and $\varepsilon$ hydride, the $\mathrm{ZrH}_{1: 66}$ to $\mathrm{ZrH}_{2}$, fct structures [3]. Figure 1 shows the $\mathrm{Zr}-\mathrm{H}$ binary system phase diagram obtained from a journal [4].

A Zircaloy cladding is usually tubular with a diameter of about $10 \mathrm{~mm}$, a wall thickness of about 
$0.6 \mathrm{~mm}$, and a length of about $4 \mathrm{~m}$. It is usually recrystallized and, in some designs of fuel rod, the inside surface is lined with another zirconium alloy or pure zirconium to prevent stress corrosion cracking by fission products such as iodine [5]. If the cladding wall is penetrated during operation, for example by fretting, water from the heattransport system can enter the fuel cavity where, because of the low pressure, steam is produced. Much hydrogen is generated because the steam oxidizes the fuel and the inside surface of the cladding, reducing the partial pressure of oxygen and leaving a gas rich in hydrogen. This process is called "oxygen starvation". At some distance from the primary defect, the gas stream becomes almost pure hydrogen by breaking the protective oxide layer down. Consequently, copious quantities of hydrogen may be absorbed by the cladding [6]. Sometimes, "sunbursts" of hydride are formed on the inside surface. Although the pure $\mathrm{Zr}$ liner is often found to be completely corroded, therefore contributing hydrogen to the inventory and stress through expansion via the oxide, it is not a necessary requirement for the secondary damage because unlined fuel cladding behaves in a similar manner. With fuel expansion during fuel shuffling, the hydrided cladding is stressed which leads to crack initiation. The cracks grow through-wall and may be over $1 \mathrm{~m}$ long. The fractures are characterized by brittle regions in "striations" or "chevrons", with the crack front often leading towards the outside surface of the cladding [7]. The mechanism of cracking appears to be a form of delayed hydride cracking (DHC) perhaps exacerbated by a continuous additional supply of hydrogen from the steam inside the fuel element [8].

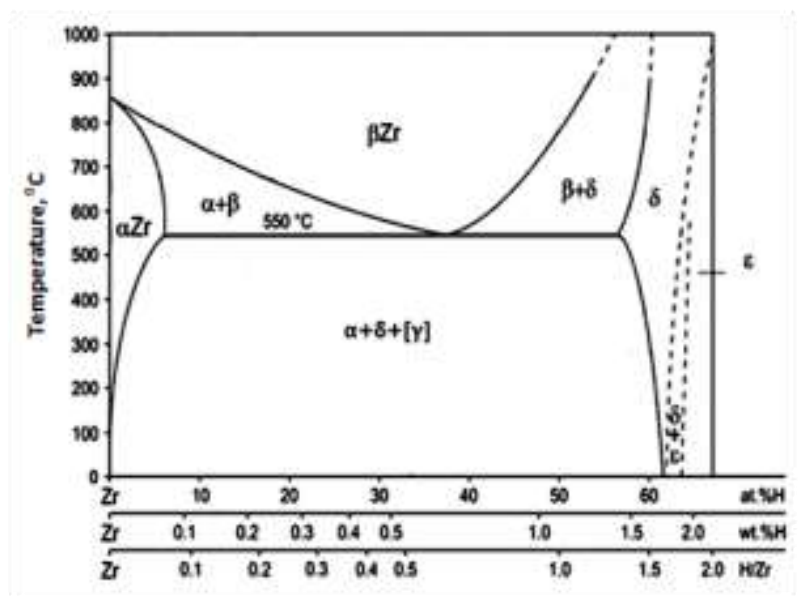

Fig. 1. Zr-H Binary Phase Diagram [3].

DHC in zircaloy- 2 and zircaloy-4 has been researched by many researchers and the results have been reported in many journals $[9,10]$. DHC is a subcritical crack growth mechanism occurring in zirconium alloys, as well as in other hydrideforming materials, that requires the formation of brittle hydride phases at the tip of a crack and subsequent failure of that hydride resulting in crack extension. Hydrogen dissolved in the zirconium alloy is transported by diffusion processes to the crack tip where it precipitates as a hydride phase. When the precipitate attains a critical condition, related to its size and the applied stress intensity factor, a fracture ensues and the crack extends through the brittle hydride and arrests in the matrix. Each step of crack propagation results in crack extension by a distance of approximately the length of the hydride. This stepwise progression may leave striations on the fracture surface corresponding to each step that can often be observed with a low-power light microscope. The amount of hydrogen dissolved in the metal and available for diffusion to the crack tip is a critical determinant of the cracking phenomenon.

In this paper, a preliminary investigation on the hydride formation in zircaloy-4 cladding was conducted at various temperature, starting from $350^{\circ} \mathrm{C}$, which is referred to the cladding operating temperature, up to $600^{\circ} \mathrm{C}$ as a representative temperature above eutectoid point based on binary phase diagram of $\mathrm{Zr}-\mathrm{H}\left(550^{\circ} \mathrm{C}\right)$ under excessive hydrogen at various pressures, up to a maximum of 1200 mbar. The pressure value is determined based on allowable operating safety limits of hydriding system. This study aims to determine the influence of hydrogen by these parameters. The expected result of this experiment is the emergence of the hydride phase as an indicator of deterioration in mechanical properties.

\section{EXPERIMENTAL METHODS}

\section{Pre-hydriding}

The zircaloy-4 tubes $(13.11 \mathrm{~mm}$ outer diameter and $0.58 \mathrm{~mm}$ thickness) received from the Center for Nuclear Fuel Technology were used in this experiment. Samples were cut by diamond cutting with almost identical dimension (Fig. 2).

To remove the material affected by the mechanical cutting process, all samples were chemically cleaned in nitric acid at $70^{\circ} \mathrm{C}$ for several minutes. The chemical composition was verified by Thermo ARL Quant'x EDXRF spectrofotometer and phase identification as-received samples was measured by Panalytical Empyrean $\mathrm{X}$-Ray Diffractometer with $\mathrm{Cu}-\mathrm{K} \alpha$ radiation $(\lambda=1.541874 \AA)$. 

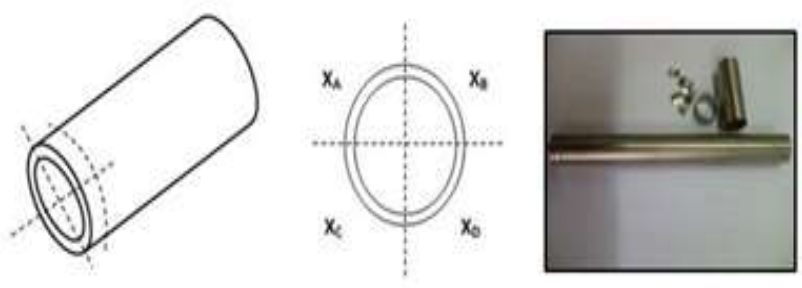

Fig. 2. Cutting diagram of zircaloy-4 tube.

\section{Hydriding}

The hydride formation experiments were performed using zircaloy- 4 chips by exposing them to hydrogen process gas with pressure, time, and temperature as process variables. The experimental apparatus consisted of a Sievert's system equipped with pressure and temperature sensors developed by the authors. The vessel is a closed-end alumina tube sealed with a stainless steel end cap gasket that has been configured to allow the process gas to enter and exit the vessel as well as a thermocouple to monitor sample temperatures. The process gas enters the vessel through a stainless steel pipe that delivers the gas within the sealed quartz tube. The hydrogen pressure in the system can be read via pressure indicator. The hydriding experiment was conducted in a Sievert's system under high vacuum condition with a maximum operating pressure of $1200 \mathrm{mbar}$ at varied temperatures of $350^{\circ} \mathrm{C}, 500^{\circ} \mathrm{C}, 550^{\circ} \mathrm{C}$, and $600^{\circ} \mathrm{C}$, respectively. The procedure of the experiment has been published elsewhere [11].

\section{Post-hydriding}

For the experiments, the samples used were divided into several groups, with each group intended for a different analysis. After hydriding treatment, several sample groups were analyzed with an ELTRA ONH-2000 oxygen/nitrogen/hydrogen analyzer to measure hydrogen content. Several other group samples were measured by XRD to investigate possible existing phase after hydriding processes. For metallurgical examinations, samples were prepared by several successive stages of grinding, using increasingly fine abrasive particle size at each stage, starting with 500-grit paper and finishing with 2400-grit paper before polishing with special cloth and etching with solution consisting of $25 \mathrm{cc} \mathrm{H}_{2} \mathrm{O}_{2}$, $27 \mathrm{cc}^{\mathrm{HNO}}$, and 8-10 drops of HF, swabbing for 5-10 seconds. Microstructure observations were performed using a JEOL JSM-6510LA Scanning Electron Microscope.

\section{RESULTS AND DISCUSSION}

\section{Pre-hydriding characterization}

Pre-hydriding characterization of as-received samples is necessary for ensuring that the proper material was used, because not enough documentation was available for this material. In addition, by knowing the initial data of this material, any changes of material characteristic after the process can be identified clearly. From the XRF result, the material's chemical composition was confirmed by Sandvik and Westinghouse for zircaloy-4 as listed in Table 1.

Table 1. Chemical composition of zircaloy-4 by XRF.

\begin{tabular}{cccc}
\hline Element & Current Specimen & Sandvik[12] & Westinghouse[12] \\
\hline $\mathrm{Zr}$ & $98.27 \%$ & $98.34 \%$ & $98.34 \%$ \\
$\mathrm{Sn}$ & $1.40 \%$ & $1.26 \%$ & $1.34 \%$ \\
$\mathrm{Fe}$ & $0.21 \%$ & $0.23 \%$ & $0.21 \%$ \\
$\mathrm{Cr}$ & $0.12 \%$ & $0.12 \%$ & $0.11 \%$ \\
\hline
\end{tabular}

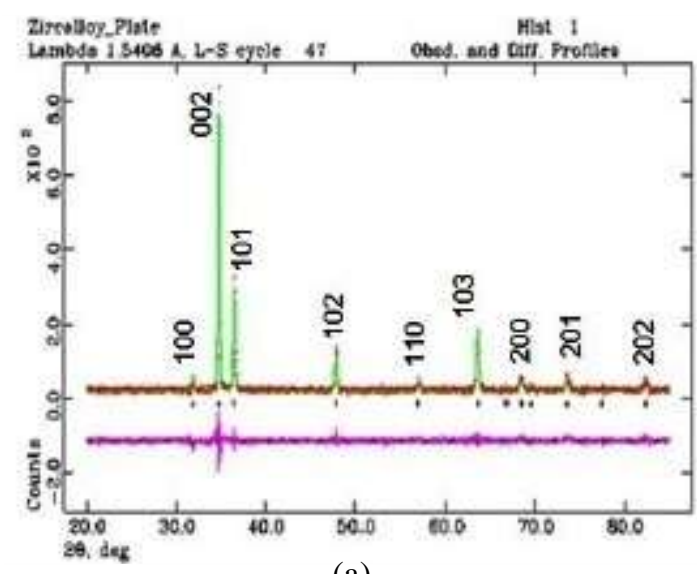

(a)

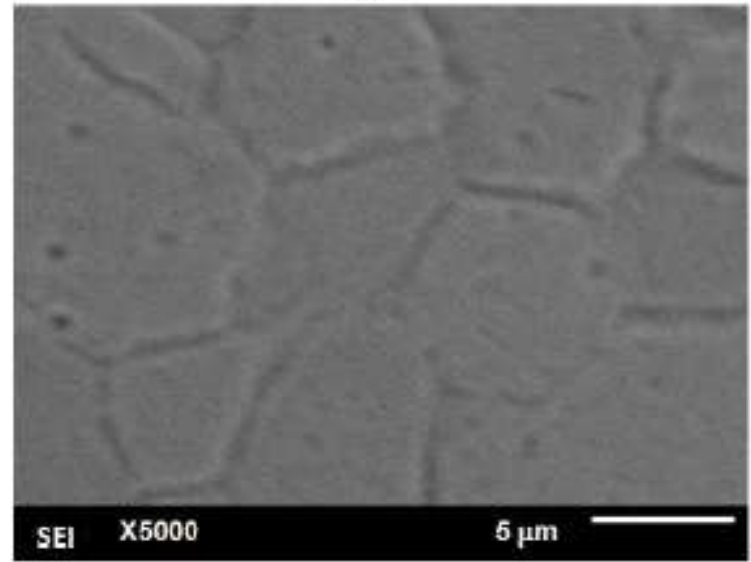

(b)

Fig. 3. The Zircaloy-4 XRD pattern (a) and microstructure by SEM (b) before hydriding.

Figure 3 shows the microstructure and GSAS (General Structure Analysis System) pattern 
before hydriding. The measured diffraction pattern was fitted by Rietveld analyses using the GSAS software. The XRD pattern shows peak with hcp crystal system and $\mathrm{P}_{3} / \mathrm{mmc}$ (194) space group. The lattice parameters are $\mathrm{a}=\mathrm{b}=3.2393(3) \AA$ and $\mathrm{c}=5.1535(4) \AA$ with $\alpha=\beta=90^{\circ}$ dan $\gamma=120^{\circ}$. These results were confirmed by microstructure observation that showed that the microstructure of the zircaloy-4 alloy consisted of a single-phase hcp $\alpha-\mathrm{Zr}$ with grains size with a mean diameter of approximately $5 \mu \mathrm{m}$. There are differences in composition among the specimens, where the current specimen show the highest Sn content.

\section{Hydrogen absorption}

On hydriding with gaseous hydrogen charging technique, the amount of hydrogen absorbed by zircaloy- 4 at each operating temperature can be approximated by a variety of methods. Two methods were used, namely, first, by using the ideal gas equation which produces PCI diagram as shown in Fig. 4, and second, by direct measurement by using an ELTRA ONH-2000 Analyzer.

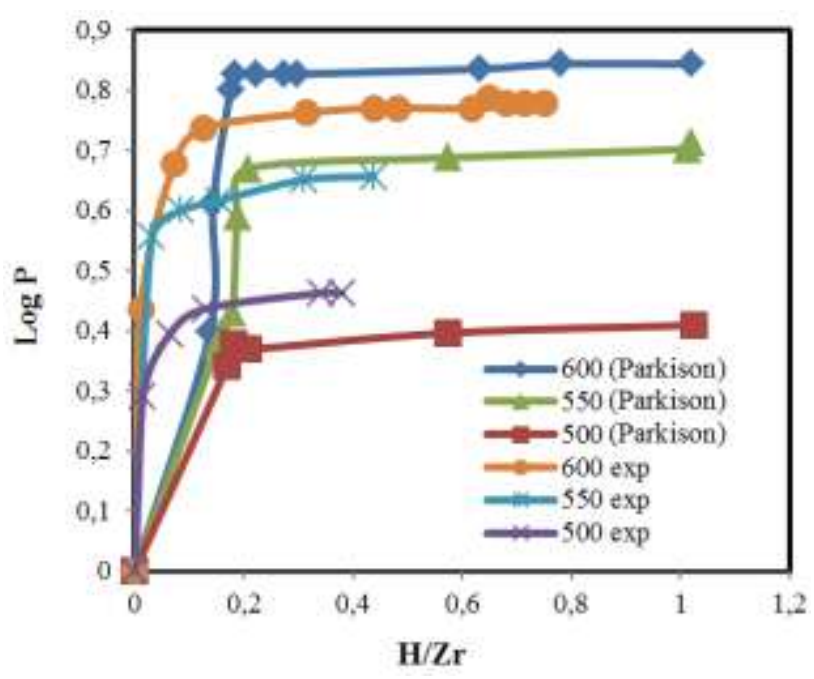

Fig. 4. PCI diagram of hydrogen absorption.

Figure 4 shows the hydrogen absorption characteristics of the specimens at elevated temperatures presented together with that reported by Parkison [13]. Both data show that the plateau regions are still in the $\alpha+\delta$ region. The differences can be explained by differences in the hydriding methods, namely temperature, pressure, hydrogen sources, and hydrogen charging time, as they contribute to the kinetics aspects of the specimen. In addition, the different composition of the specimens also support the quantity of hydrogen absorption of the specimen, i.e., a higher Sn content reduces the hydrogen absorption.

Figure 5 shows hydrogen content in the specimen after hydriding at varied temperature from $350^{\circ} \mathrm{C}$ to $600^{\circ} \mathrm{C}$ presented together with that of the experimental result obtained by Vizcaino et al. [14]. The figure shows that hydrogen content in the experiment as determined by using the $\mathrm{ONH}$ hydrogen analyzer in is higher than that obtained by Vizcaino. The difference in results is suggested from the different experimental methods. The present experiment used pure hydrogen at pressure of up to 1200 mbar or under excessive reaction, while Vizcaino used sulfuric acid as the hydrogen sources by cathode charge technique with a current as the power for hydrogen diffusion energy. Consequently, the concentration of hydrogen purged in the system was much higher than that conducted by Vizcaino.

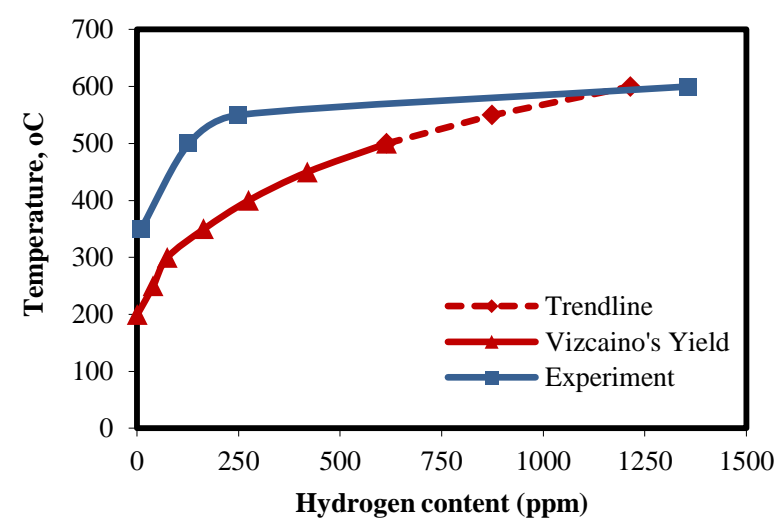

Fig. 5. Equlibrum hydrogen content-pressure at elevated temperature.

The presence of hydrogen causes precipitation of hydride in the specimen in needlelike form that will be discussed by microstructure evolution. The figure informs the endurance of the zircaloy-4 specimen against elevating temperature.

\section{XRD analysis}

Before hydriding the specimen was identified as mostly $\mathrm{Zr}$. At a temperature of $350^{\circ} \mathrm{C}$, the specimen was still stable with no Zr-hydride identified. After the temperature was increased to $500^{\circ} \mathrm{C}, 550^{\circ} \mathrm{C}$, and finally to $600^{\circ} \mathrm{C}$, it was found that the formation of $\mathrm{Zr}$-hydride started to occur. Figure 6 shows the XRD refinement results of the specimens before and after treatment. It is shown that 
at a temperature of $500^{\circ} \mathrm{C}$ hydrogen absorption started to occur to form $\alpha+\delta$-hydride phase. No $\gamma$-hydride phase was found.

Daum et al. [12] confirmed in their research that $\delta$-hydride peaks began to grow at a hydrogen content above $1250 \mathrm{ppm}$. At a higher content, about $3000 \mathrm{ppm}$, a number of $\gamma$-hydride starting to form although $\delta$-hydride is still the majority phase. At more hydrogen contents, approximately $6000 \mathrm{ppm}$, the peaks were associated with the $\varepsilon$-hydride phase. Peshenichkov et al. [15] found that the increase of hydrogen content appears as the first and the most intensive peak $\delta\{111\}$ and then $\delta\{200\}$ and rise of $\gamma\{311\}$ after the hydrogen content reach $1300 \mathrm{ppm}$. For $\gamma$-phase only peaks corresponding to $\{111\}$ and $\{311\}$ were visible. The peak $\gamma\{111\}$ appears as a single peak only after $3000 \mathrm{ppm}$ of hydrogen. Further increase of hydrogen content has not led to the formation of new peaks but to redistribution of the intensities of the already existed ones. At extreme high hydrogen content values above $8000 \mathrm{ppm}$ the peak of the $\delta$ zirconium hydride becomes dominant. From the GSAS refinement at a temperature of $600^{\circ} \mathrm{C}$ hydrided sample has $\delta$-hydride mass fraction of $0.14 \%$. It is noted that the $\gamma$-phase present together in the $\alpha-\delta$ equilibrium phase region. The $\gamma$-phase could be the product of a peritectoid reaction between $\alpha$ and $\delta$-phases. Zielinski [16] found that the peritectoid reaction occurs at $225^{\circ} \mathrm{C}$ between $\alpha$ terminal solid solution and the fcc $\delta$-hydride leading to the formation of a stable $\gamma$-hydride due to the fast cooling. X-ray studies carried out at room temperature showed that the $\alpha$-and /or $\delta$-phases coexisted with small amounts of the $\gamma$-phase after all heat-treatments for compositions up to $\mathrm{ZrH}_{1.44}$ (59 at\% hydrogen). If the $\gamma$-hydride is stable below $255^{\circ} \mathrm{C}$, then all specimens prepared and heattreated below this temperature should have contained substantial amounts of $\gamma$-phase. However, a survey of literature does not support the existence of this peritectoid reaction. It has been demonstrated by the current experiment, where no fast cooling was conducted, no $\gamma$-hydride was observed, as presented in Fig. 6.

As shown in Fig. 6, it also observed the presence of some $\mathrm{ZrO}_{\mathrm{x}}$ with $\mathrm{x}$ being equal to or less than 2 , especially at $600^{\circ} \mathrm{C}$, an indication that some oxygen uptake or some oxidation may have occurred and diffused into the specimen. The presence of oxygen should be from the incomplete evacuation, during specimen treatment, or due to the purity of gas. Dupim et al. have found that hydride formation started at about $437^{\circ} \mathrm{C}$ with the exothermic solution of $\mathrm{H}$ in the metal lattice and the precipitation of $\mathrm{Zr}-\mathrm{H}$ in different phases [17]. Meanwhile, the thin oxide layer must have started to form at above $300^{\circ} \mathrm{C}$, since below this temperature no reaction was observed in the tested specimen. Above this temperature, the deliberately protective oxide layer starts to dissolve into the metal, and at about $437^{\circ} \mathrm{C}$ the hydrogen atoms from the dissociated $\mathrm{H}$ molecules start to diffuse into the metal. Similar to the Dupim's results, Fig. 6 also showed that there is no oxide identified at a temperature of $350^{\circ} \mathrm{C}$ and gradually peaks of oxide appear along the elevated temperature which is supported by refinement and quantitative analyses using Rietvield method.

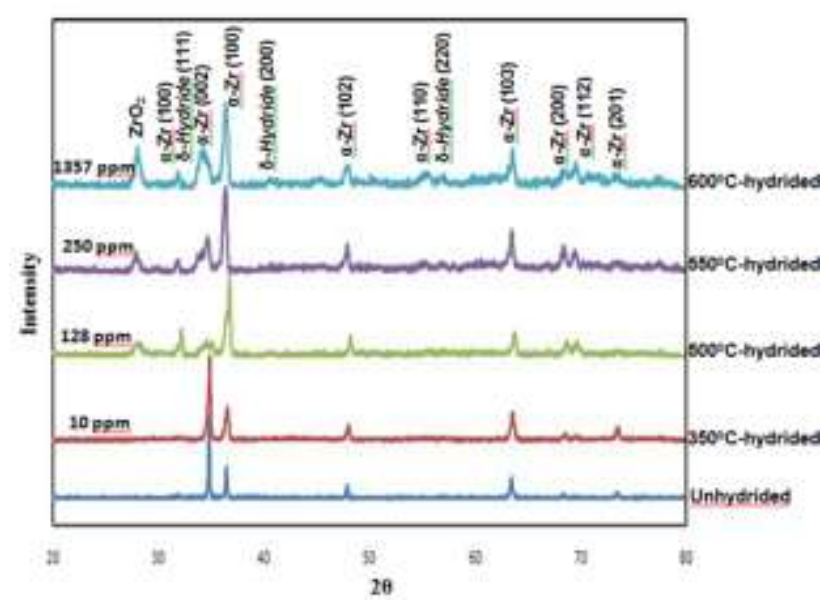

Fig. 6. XRD pattern of unhydrided and hydrided zircaloy-4.

\section{Microstructure evolution}

The microstructural changes of the zircaloy-4 samples before and after hydriding are illustrated in Figs. 7 (a) - (d). Very fine microstructure is shown in Fig. 7 (a), even grains are not clearly visible using optical microscope. At $500^{\circ} \mathrm{C}$ hydrogen atmosphere, the microstructure of the hydrided sample consisted of $\alpha-\mathrm{Zr}$ grains and needle-like which indicates the presence of hydrides (Fig. 7 (b)) and become thicker at $550^{\circ} \mathrm{C}$ (Fig. 7 (c)) and $600^{\circ} \mathrm{C}$ (Fig. 7 (d)). The hydride morphologies vary with increase of operating temperature. The aperture on microstructure showed cracks in several areas in the test material. 

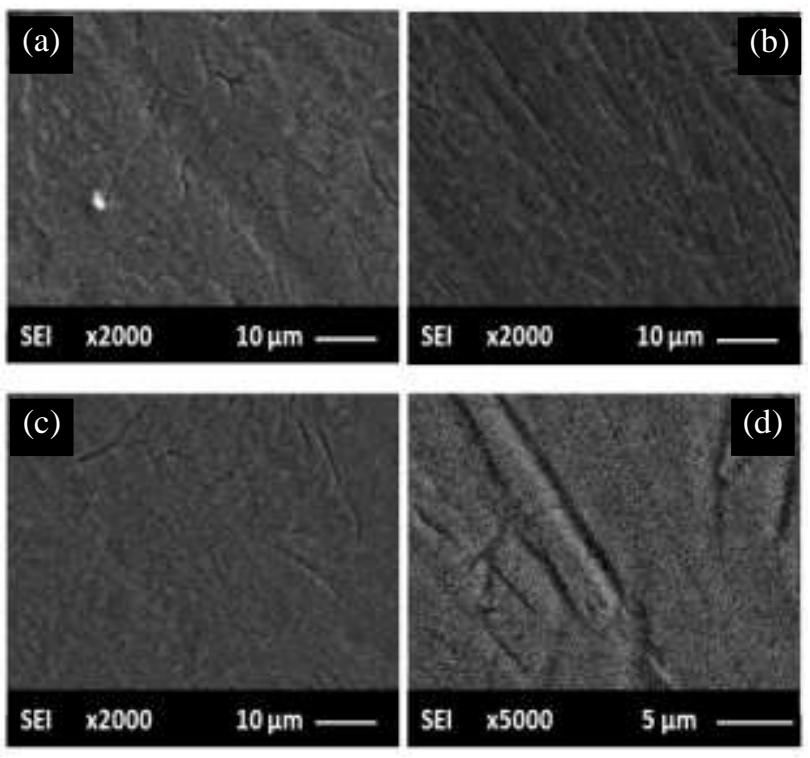

Fig. 7. Microstructure evolution at (a) $350^{\circ} \mathrm{C}$, (b) $500^{\circ} \mathrm{C}$, (c) $550^{\circ} \mathrm{C}$ and (d) $600^{\circ} \mathrm{C}$.

Lattice defects such as vacancies may occur during fabrication process of zircaloy-4 tube, which supports the increase of hydride nucleation possibilities. Hydride nucleation is not homogeneous in zircaloy-4. In general, hydride nucleation mainly occurs at grain boundaries, but in some cases, many researchers have observed hydrides within the grains. Wang [18] found in his study that the sharp structures in the form of scratches or cracks were hydride platelets that can occur at the grain boundaries and within the grains as shown in Fig. 8. Some studies suggested that these structures are hydrides, while several other studies claimed that these structures could be from scratches that occurred during the preparation of the material before observation $[15,19]$. The existence of such structures indicated the occurrence of brittleness due to hydriding on the test specimens.

As the temperature increased, the needles became thicker and the hydride concentration increased. Finally, due to the combination effects of defect and large concentration, the nucleation and growth of hydrides are facilitated in the zircaloy-4 specimens. Referring to the XRD analysis, where the presence of $\delta$-hydride phase was indicated, the appearance of the structure mentioned by Wang [18] as hydride platelets can be explained due to the brittle nature of $\delta$-hydride either when it is at room temperature or at high temperature. It has been proven during preparation of test material for the XRF purposes. When the test material is heated to $600^{\circ} \mathrm{C}$ without hydrogen it does not have any problem when it was pressed to shape the test material into flat form, whereas the hydrided material broke into several parts. This evidence explains the degradation of the mechanical properties of zircaloy-4 could be happened due to the presence of the hydride phases.
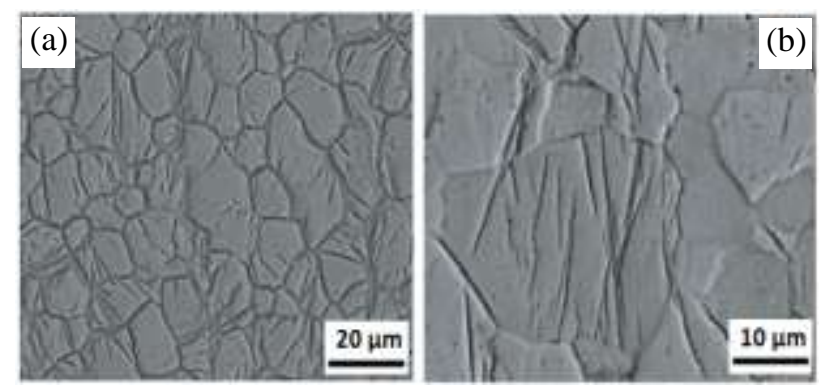

Fig. 8. Hydride platelets: (a) at the grain boundaries and (b) within the grains [19].

\section{CONCLUSION}

Hydriding of zircaloy-4 at elevated temperatures from $350^{\circ} \mathrm{C}$ to $600^{\circ} \mathrm{C}$ have been performed. There was no $\mathrm{Zr}$-hydride formation at temperature of $350^{\circ} \mathrm{C}$. At $500^{\circ} \mathrm{C}$ hydrogen started to react with zircaloy-4 to form $\mathrm{Zr}$-hydride. For temperatures of $500^{\circ} \mathrm{C}$ to $600^{\circ} \mathrm{C}$ only the $\alpha+\delta$ hydride phase was observed and no $\gamma$-hydride was identified. The hydrogen contents measured were $10,128,250$, and $1357 \mathrm{ppm}$ at $350^{\circ} \mathrm{C}, 500^{\circ} \mathrm{C}$, $550^{\circ} \mathrm{C}$, and $600^{\circ} \mathrm{C}$, respectively. The peaks of $\alpha-\mathrm{Zr}$ were not disturbed by the hydriding temperature.

Microstructure observations showed that the needle-like objects started forming at a temperature of $500^{\circ} \mathrm{C}$ followed by the formation of hydride phases and the lattice defects in the specimen. Increasing the temperature even higher led to the growth of Zr-hydride nucleation, indicating the brittleness of the specimen.

\section{REFERENCES}

1. M.S. Blackmur, J.D. Robson, M. Preuss et al., J. Nucl. Mater. 464 (2015) 160.

2. L.M.E. Ponzoni, J.I. Mieza, E.D. Las Heras et al., J. Nucl. Mater. 439 (2013) 238.

3. S.K. Nouduru, M.K. Kumar, V. Kain et al., J. Nucl. Mater. 470 (2016) 197.

4. M. Grosse, M. Van Den Berg, C. Goulet et al., J. Phys.: Conf. Ser. 340 (2012) 1.

5. M.L. Rossi and C.D. Taylor, J. Nucl. Mater. 458 (2015) 1.

6. C. Zhao, X. Song, Y. Yang et al., Int. J. Hydrogen Energy 38 (2013) 10903. 
7. M.K. Samal, G. Sanyal and J.K. Chakravartty, Engineering Failure Analysis 18 (2011) 2042.

8. E. Hong, D.C. Dunand and H. Choe, Int. J. Hydrogen Energy 35 (2010) 5708.

9. S. Suman, M. Kaleem, M. Pathak et al., Int. J. Hydrogen Energy 40 (2015).

10. J. Bair, M. Asle, M. Tonks et al., J. Nucl. Mater. 466 (2015) 12.

11. H. Suwarno, Atom Indonesia 40 (2014) 113.

12. R.S. Daum, Y.S. Chu and A.T. Motta, J. Nucl. Mater. 392 (2009) 453.

13. A.J. Parkison, Hydride Production in Zircaloy4 As a Function of Time and Temperature,
Master of Science Thesis, Texas A\&M University (2008).

14. P. Vizcaíno, A.V. Flores, P.B. Bozzano et al., J. ASTM Int. 8 (2011) 754.

15. A. Pshenichnikov, J. Stuckert and M. Walter, Nucl. Eng. Des. 283 (2015) 33.

16. A. Zielinski, S. Sobieszczyk, Int. J. Hydrogen Energy 36 (2011) 8619.

17. S. Dupim, J.M.L. Moreira, S. Luiza et al., J. Nucl. Mater. 427 (2012) 121.

18. Z. Wang, U. Garbe, H. Li et al., J. Nucl. Mater. 436 (2013) 84.

19. Z. Wang, U. Garbe, H. Li et al., Journal of Applied Crystallography 47 (2014) 303. 